
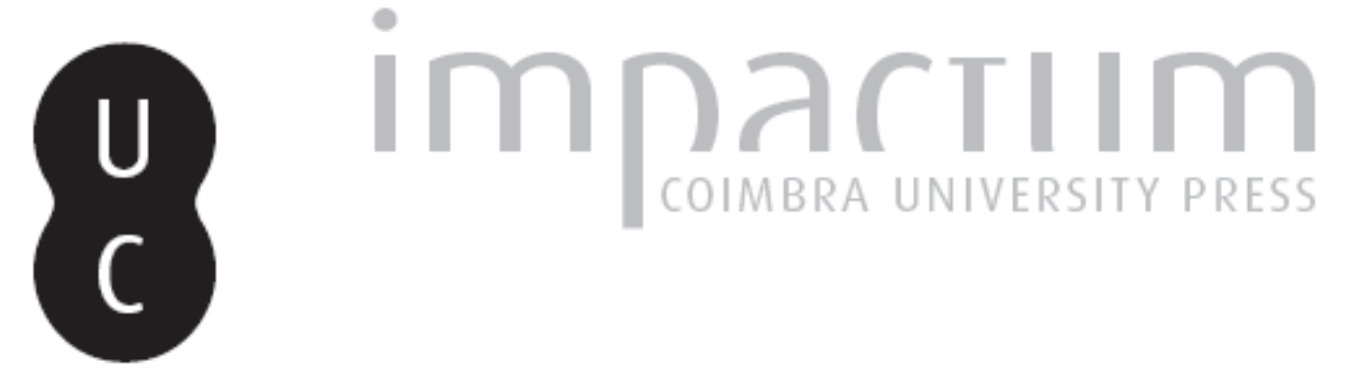

\title{
[Recensão a] Nico Carpentier, Media e Participação
}

\author{
Autor(es): $\quad$ Montargil, Filipe
}

Publicado por: Imprensa da Universidade de Coimbra

URL persistente:

URl:http://hdl.handle.net/10316.2/43205

DOI:

DOI:https://doi.org/10.14195/2183-6019_5_8

Accessed : $\quad$ 26-Apr-2023 13:27:52

A navegação consulta e descarregamento dos títulos inseridos nas Bibliotecas Digitais UC Digitalis, UC Pombalina e UC Impactum, pressupõem a aceitação plena e sem reservas dos Termos e Condições de Uso destas Bibliotecas Digitais, disponíveis em https://digitalis.uc.pt/pt-pt/termos.

Conforme exposto nos referidos Termos e Condições de Uso, o descarregamento de títulos de acesso restrito requer uma licença válida de autorização devendo o utilizador aceder ao(s) documento(s) a partir de um endereço de IP da instituição detentora da supramencionada licença.

Ao utilizador é apenas permitido o descarregamento para uso pessoal, pelo que o emprego do(s) título(s) descarregado(s) para outro fim, designadamente comercial, carece de autorização do respetivo autor ou editor da obra.

Na medida em que todas as obras da UC Digitalis se encontram protegidas pelo Código do Direito de Autor e Direitos Conexos e demais legislação aplicável, toda a cópia, parcial ou total, deste documento, nos casos em que é legalmente admitida, deverá conter ou fazer-se acompanhar por este aviso.

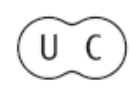


revista de comunicação,

jornalismo e espaço público

\section{5}

Periodicidade

Semestral

Imprensa da Universidade de Coimbra

Coimbra University Press

\section{mediapolis}

crises e os processos comunicativos

crisis and communicative process

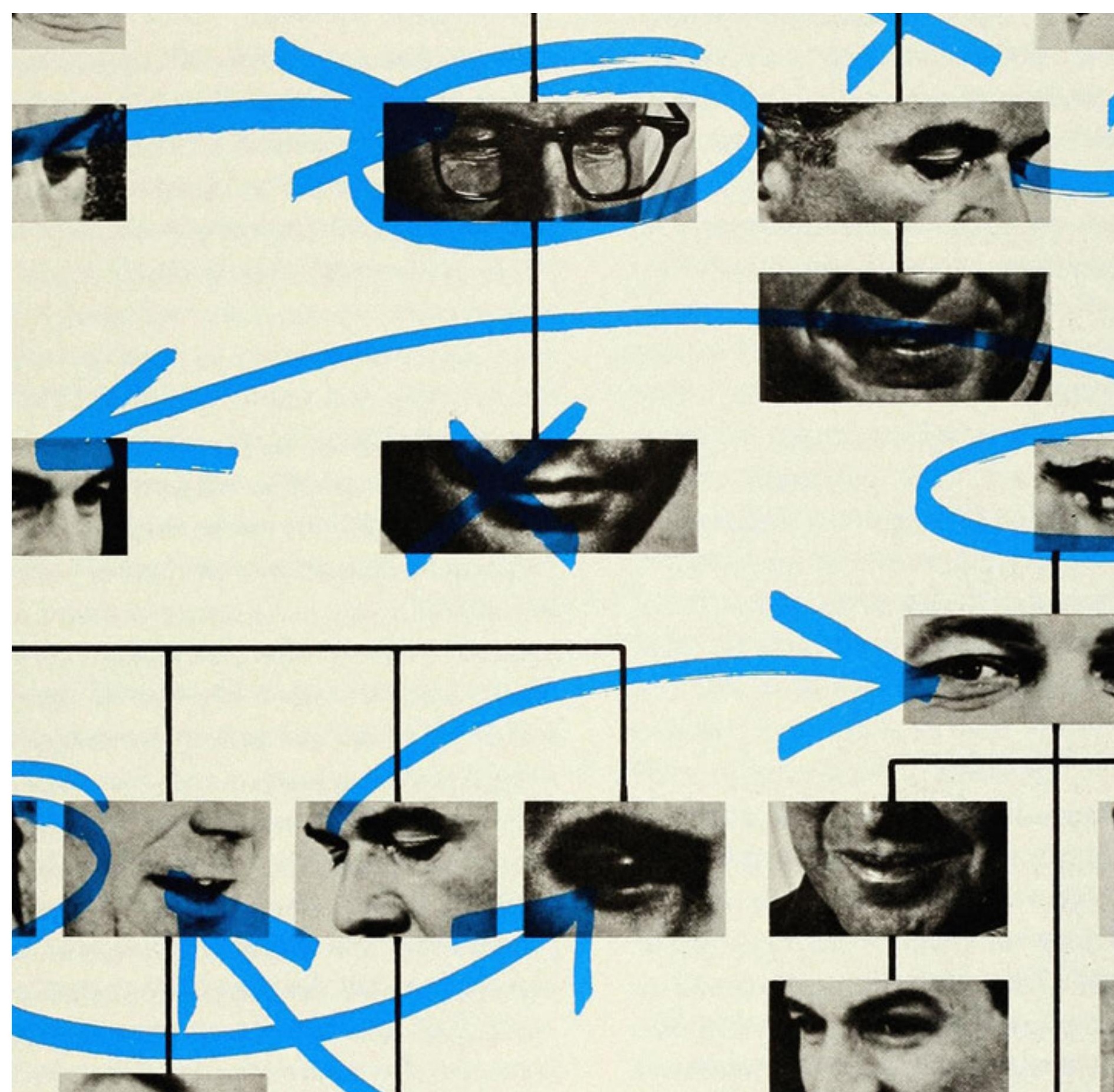




\section{Recensão Crítica}

Nico Carpentier, Media e Participação, Porto: Media XXI, 2017, 586 p.

https://doi.org/10.14195/2183-6019_5_8

Carpentier apresenta em Media e Participação, agora editado em Portugal através da Media XXI e originalmente publicado em língua inglesa em 2011, uma discussão interdisciplinar sobre a relação entre os media e o conceito de participação.

Esta obra resulta de uma reflexão consolidada ao longo de vários anos, em que artigos e capítulos publicados anteriormente pelo autor são retomados e incluídos na discussão aqui proposta.

Na primeira parte da obra é abordado o conceito de participação, recorrendo a perspetivas provenientes de quatro domínios, para além do que respeita diretamente à relação com a comunicação e com os media: (i) a ciência política, onde a noção de democracia constitui um referencial incontornável para a discussão da participação e onde esta se relaciona em permanente tensão com o conceito de representação, (ii) o planeamento do território, onde o conceito de participação assume particular relevância, quer do ponto de vista teórico quer com o desenvolvimento de projetos e experiências, por exemplo através da participação de cidadãos em processos de tomada de decisão com o apoio de sistemas de informação geográfica (SIG), (iii) os estudos de desenvolvimento, em que a participação e o envolvimento das comunidades assume um papel central na implementação de estratégias de desenvolvimento, de combate à pobreza e à exclusão social e (iv) as artes e a museologia, onde a produção de sentido invoca a participação do público e onde, por exemplo, o movimento da nova museologia coloca em destaque a noção de participação, na medida em que confere ao público a oportunidade de influenciar estes ambientes simbólicos.

Esta diversidade de áreas poderá parecer inusitada, como ponto de partida para uma discussão da participação no campo mediático. Contudo, todas estas áreas apresentam um relevante património de reflexão e de prática, em que o conceito de participação assume um papel central. Mais surpreendente será talvez, por isso, o facto de um esforço integrador e interdisciplinar desta natureza, com o destaque que Carpentier lhe confere, não surgir mais cedo.

$\mathrm{Na}$ segunda parte do livro são analisados vários estudos de caso, na área do cinema (com o filme interativo Kinoautomat, produzido na Checoslováquia em 1967), da rádio (com o projeto belga RadioSwap), da televisão (incluindo os programas Jan Publiek e Barometer, da Radiotelevisão Flamenga, na Bélgica, Video Nation, da $\mathrm{BBC}$, e a primeira versão holandesa do reality show Temptation Island) e dos novos media (com a plataforma online 16plus, criada pela Radiotelevisão Flamenga).

Esta discussão recorre a cinco dimensões secundárias de análise, na organização e sistematização dos estudos de caso: (i) o poder nas relações sociais, com as suas situações de maior ou menor assimetria, por exemplo, (ii) a identidade social e cultural e os seus mecanismos, também mediáticos, de construção e afirmação, (iii) a realidade organizacional dos media, com as suas diferentes estruturas e culturas organizacionais, por exemplo, (iv) a tecnologia 
e a forma como esta integra e enforma os processos sociais e (v) a perceção da qualidade do conteúdo comunicacional, com os problemas relacionados com a sua discussão e definição, por exemplo.

Para além de contribuírem para a ordenação e organização dos estudos de caso, estas dimensões constituem também recursos adicionais para o aprofundamento da análise, permitindo colocar em destaque perspetivas complementares, mas distintas.

Na conclusão, Carpentier destaca a contingência conceptual da participação - ou seja, a dificuldade em fixar uma aceção transversal do termo. Esta contigência decorre da multiplicidade de domínios societais em que o conceito é utilizado e do inerente combate ideológico associado e, mais do que lamentada, deve ser estudada. E é precisamente este um dos objetivos do autor, ao longo da obra. Contudo, para além de a tomar como simples objeto de estudo, o autor avança no sentido da articulação e combinação das várias dimensões.
Carpentier propõe, com esta obra, uma interessante e extensa visão interdisciplinar que envolve e articula várias áreas e procura uma perspetiva metodológica comum para aplicação aos vários estudos de caso.

A análise das relações entre os media e o conceito de participação situa-se, desta forma, acima de uma simples visão multidisciplinar, em que poderiam ser elencadas várias disciplinas mas não seria procurada a combinação e articulação entre si. Por outro lado, a síntese proposta não chega a atingir (e certamente não procuraria, aliás) um nível de integração trandisciplinar, que supere as fronteiras existentes entre as várias áreas disciplinares e ultrapasse as respetivas delimitações.

As limitações da perspetiva proposta na obra não se relacionam, eventualmente, tanto com o conceito de participação (onde o autor invoca, como vimos, várias áreas disciplinares e diferencia entre participação democrática minimalista e maximalista, ou entre micro e macro participação, por exemplo, valorizando sempre as várias formas e dimensões) mas talvez, curiosamente, com o próprio conceito de media.

Efetivamente, a noção de media não é objeto de uma atenção comparável à dedicada ao conceito de participação. $\mathrm{O}$ autor acaba, desta forma, por assumir implicitamente uma conceção talvez rígida para a delimitação do campo dos media, que se aproxima em grande medida de uma visão tradicional e conotada com a sua dimensão mainstream.

Esta conceção é percetível, sobretudo, através da análise da origem dos estudos de caso, provenientes do cinema (um caso), da rádio (um caso), da televisão (quatro casos) e de sites de redes sociais (um caso, correspondendo a uma plataforma criada por um canal de televisão).

Embora compreensível, do ponto de vista da delimitação do âmbito de estudo, esta opção acaba por quase excluir os novos media da análise e privilegiar uma perspetiva mais tradicional do campo. E acaba, também, por justificar a não inclusão de 
experiências participativas que poderiam caber numa delimitação mais alargada - de que poderiam ser exemplos o projeto MINERVA, baseado na tecnologia da televisão por cabo, desenvolvido por Etzioni (1971, 1972) ou o conceito de sondagem deliberativa, criado por Fishkin no final da década de 1980 (Fishkin, 1991; Center for Deliberative Polling, 2017).

Por outro lado, esta opção implica também a desvalorização de experiências participativas mais centradas em formas não convencionais de participação política - não tanto pela aceção do conceito de participação adotada mas, precisamente, pela forma como o conceito de media é delimitado.

Quando temos razões para pensar que as formas não convencionais de participação encerram, provavelmente, maior potencial de inovação e de mudança do que as formas convencionais (Montargil, 2010; Montargil e Santos, 2017), esta opção não pode ser considerada como neutra. Poderá sempre, contudo, constituir-se como objeto de análises que venham a retomar o tema.

\section{Referências bibliográficas}

Center for Deliberative Polling (2017). What is Deliberative Polling $®$ ? Retirado de http://cdd.stanford. edu/what-is-deliberative-polling/.

Etzioni, Amitai (1971). Cable TV: instant shopping or participatory technology, Social Policy, 2(4), 52-55.

Etzioni, Amitai (1972). Minerva: an electronic town hall, Policy Sciences, $3(4), 457-474$

Fishkin, J. S. (1991). Democracy and Deliberation: New directions for democratic reform. New Haven: Yale University.

Montargil, F. (2010). Electronic government and government transformation: technical interactivity, political influence and citizen return. In Nixon. P. \& Koutrakou, V. (Org.), E-Government in Europe: Issues and challenges (pp. 61-77.). Londres: Routledge.

Montargil, F. \& Santos, V. (2017). Citizen observatories: concept, opportunity and first experiences. In Paulin, A., Anthopoulos, L. e Reddick, C., Beyond Bureaucracy - Towards Sustainable Governance Informatisation (pp. 167-184), Cham (CH): Springer. 